\title{
Experience with Special Fiber Optic Sensors for Online Monitoring of High Voltage Stator Windings at Large Turbine Generators - Long Term Reliability and Machine Operation Diagnosis -
}

\author{
S. Strack, J. R. Weidner, Siemens AG, Energy Sector, D-45478 Mülheim a. d. Ruhr \\ T. Bosselmann, M. Villnow, M. Willsch, Siemens AG, Corporate Technology, D-91058 Erlangen
}

\section{Summary}

The increasing quantity of renewable energy in electric power generation leads to a higher flexibility in the operation of conventional power plants. Especially the turbo generator having the highest energy density has to face the influence of frequent start-stop-operation on thermal movement and vibration of the stator end windings. Large indirect cooled turbo generators have been equipped with newly designed FBG strain and temperature sensors to monitor the influence of peak load operation on transient mechanical and thermal load stress in the end winding structure. Well approved fiber optic accelerometers measure the vibration of the end windings at several turbine generators since many years of operation. The long term reliability of fiber optic vibration, temperature and strain sensors could be successfully proved during years of online operation. Analysis of these data in correlation to significant operation parameter would lead to important diagnostic information of end winding behaviour within the years and is a required key information for life time assessment of the stator winding.

\section{Introduction}

The new European grid code Entso-e [1], which defines the load conditions for the transnational high voltage overlay grid, prescribes a broader power and frequency fluctuation and steeper load ramps. Especially the component with the highest energy density in the power plant, the turbo generator, has to face these higher load demands with same good efficiency and availability.

The higher stressed generator parts like high voltage stator winding and overhangs need to be carefully monitored to ensure the design life time of about 30 years. Moreover, the influence of frequent start-stop-operation on thermal movement and vibration of the end windings has to be surveyed to avoid accelerated aging of the insulation structure due to mechanical fatigue. Online vibration monitoring of stator end windings with Fiber Optic Acceleration (FOA) Sensors, which are placed at design dependent pre-defined front-end locations, becomes an important diagnostic tool for generators running in peak load condition in combustion and combined cycle power plants. In Figure 1 a section view of a typical indirect gas cooled generator stator and rotor is given.

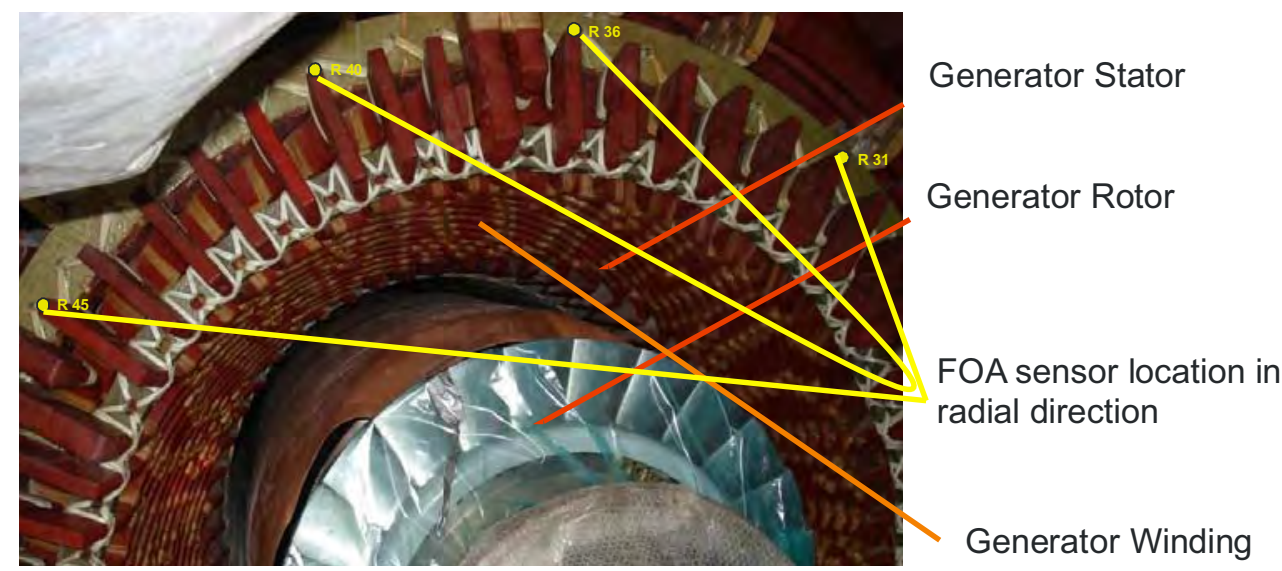

Fig 1: Section view of a generator with fiber optic sensor located at stator winding front ends 
At the very front-end of stator end windings FOA sensors yellow marked R31 - R36 - R40 - R 45 were installed to monitor the vibration behaviour during flexible operation regime. Together with other type of fiber optic sensors like temperature and strain sensors it is expected to get better information on stress dependent changes in the end winding structure.

\section{Fiber Optic Sensor Technologies used in Turbine Generators}

For fiber optic vibration sensors used in generator diagnostics a light intensity modulation based technology is applied in most cases. The fiber optic temperature and strain sensors installed in generators are based on Fiber-Bragg-Grating (FBG) technology. The experience in installation and maintenance and long time behavior of sensors is focused on these two fiber optical technologies.

\subsection{Vibration Sensor}

\subsubsection{Light Intensity Modulation Technology}

Fiber optic vibration sensors applied at generators use the effect of modulating the light intensity by the excitation of a specific spring mass system coupled with the flexible end of glass fiber. The vibration of the internal flexible fiber-mass system is linear related to the external vibration impact. The sketch shown in Figure 2 describes the principle of a fiber optic vibration sensor.

Fig.2: Principle of fiber optic vibration sensor consisting of a flexible multimode fiber with mass element on top shining on a slantwise reflecting surface

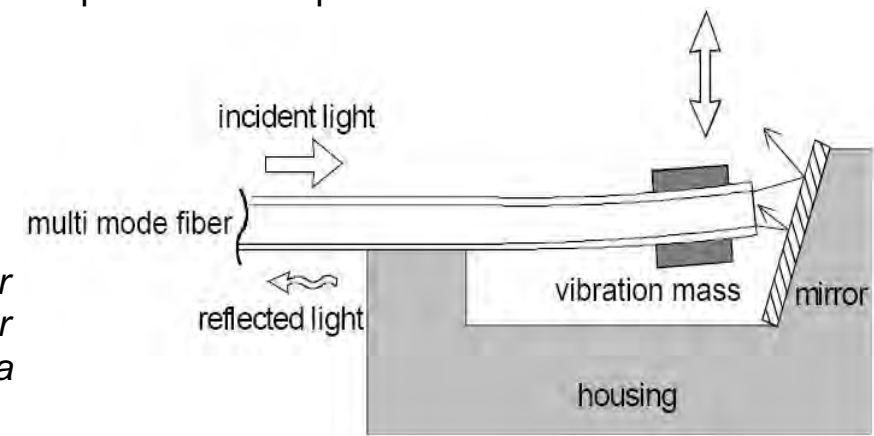

Light is emitted from the end of a multi mode fiber and reflected back to the fiber via a slantwise mirror. When the fiber tip is moved due to its seismic mass, the distance to the mirror is varied and therefore the amount of back reflected light coupled into the fiber. The light intensity varies with acceleration. These changes are analyzed by a special signal conditioning unit.

To fulfill good sensitivity and long time stability requirements at the high thermal, electromagnetic and mechanical operational stresses at generators the knowledge of the long time behaviour of the fiber optic sensor is necessary. It is extremely important that one can separate a signal variation coming from the monitored generator winding from possible trend generated by the sensor itself.

\subsubsection{Long Time Stability of Fiber Optic Vibration Sensors}

For verifying long time wear effects related to vibration level change of the end windings it is important to distinguish between the behaviour of the end winding structure and the FOA sensor itself. The analysis of the eigenvectors of the generator part and of FOA sensor is very valuable tool to solve this subject. Figure 3 shows the FOA fixation at the winding front-end and gives a simple model of a coupled spring-mass system with one Degree-of-Freedom (DOF).

Fig. 3: Generator winding front-end connection with fiber optic vibration sensor FOA and appropriate spring-mass-system model used for signal analysis

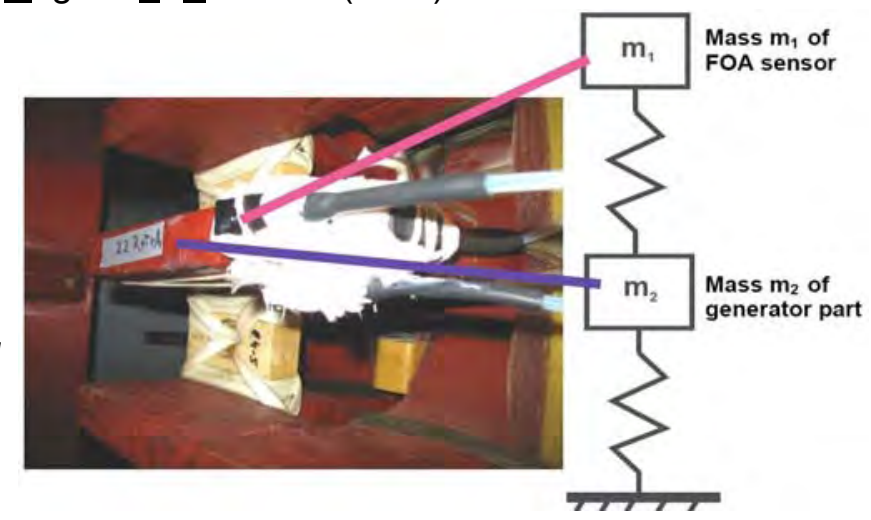


Of course the mass-spring-configuration of the end winding basket is much more complicated than this simple model given here. But because of the fact, that decoupling of FOA sensor and end winding system is needed only the one DOF model fits good enough. The vibration behaviour of the mass-spring-system model according to Figure 3 is given in equation (1) describing displacement $x$ of winding part under the impact of force $F$ with mass $M$, damping $D$ and stiffness $C$ of the model:

$$
\frac{\overrightarrow{d^{2} x}}{d^{2} t} \overleftrightarrow{M}+\frac{\overrightarrow{d x}}{d t} \overleftrightarrow{D}+\vec{x} \overleftrightarrow{C}=\vec{F}
$$

In order to separate the long time behaviour of the generator winding component from the fiber optic sensor itself the mixed time domain signal of different vibration frequency sources could be transformed into frequency domain analysis. Figure 4 demonstrates the relationship between sinwave excitation forms during normal load operation in time domain and analysis of the frequencyresponse-functions within frequency domain visualization.

\section{Different sin-wave excitation forms during normal generator operation}

$F_{1}(t)=\sin \omega t+\varphi \rightarrow f_{1}$

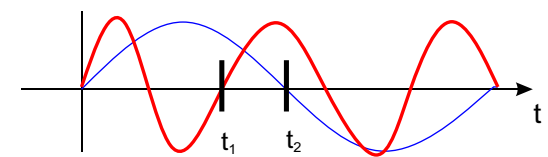

$F_{2}(t)=\sin 2.5 \cdot \omega t+\varphi \rightarrow f_{2}$

Fig. 4: Separation of different vibration frequency sources using transformation from time domain into frequency domain and analysis of frequencyresponse-functions

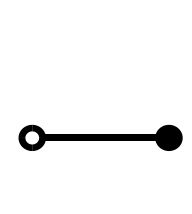

During normal load operation turbo generator stator windings will be excited by the following three major sources of force:

(1) Bearing and shaft vibration acting at the $1^{\text {st }}$ grid harmonic (e.g. $50 \mathrm{~Hz}$ ) for 2-pole generators,

(2) Magnetic forces of rotating flux field in stator core also called "core ovalisation" forces acting at the $2^{\text {nd }}$ grid harmonic (e.g. $100 \mathrm{~Hz}$ ) and

(3) Electromagnetic forces generated by stator current in the winding with grid frequency. The stator current generates forces with a frequency of the $2^{\text {nd }}$ grid harmonic (e.g. $100 \mathrm{~Hz}$ ).

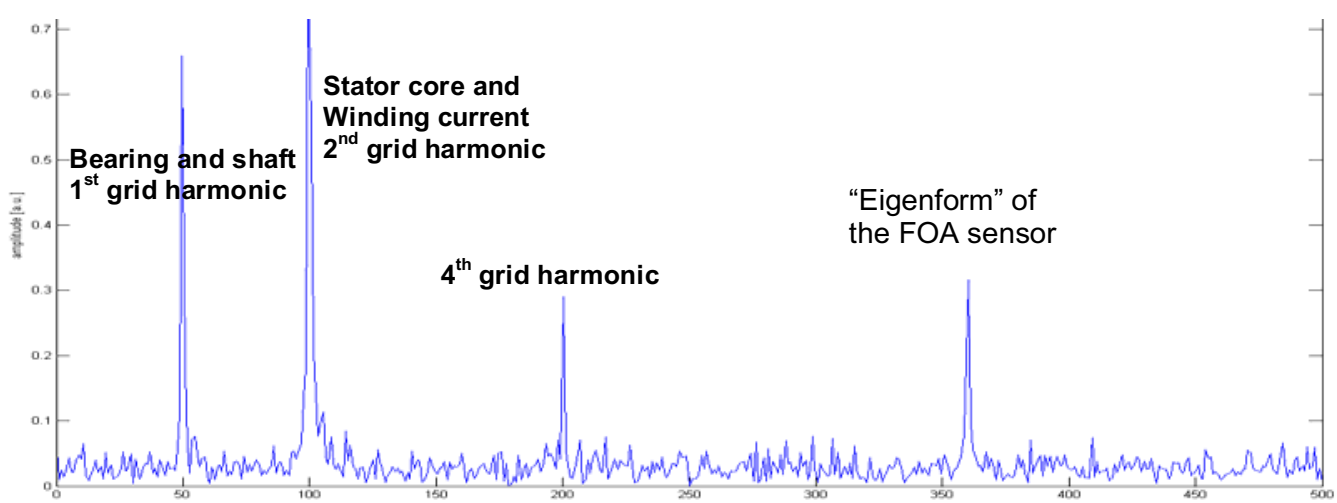

Fig 5: Example of frequency spectrum of SFOA sensors placed at the outmost position of the stator end winding of an indirect cooled 2-pole turbo generator 
Figure 5 gives an example of the frequency spectrum of a 2-pole generator that was taken in full load condition with FOA sensors placed at the outmost position of the stator end winding. Most of the FOA sensors measure vibration in radial direction, because of excitation DOF during normal operation. With the development of the new Siemens sensor (SFOA), which uses a band-pass-filter system to switch off the eigenform of the sensor, additional features for signal analysis are available.

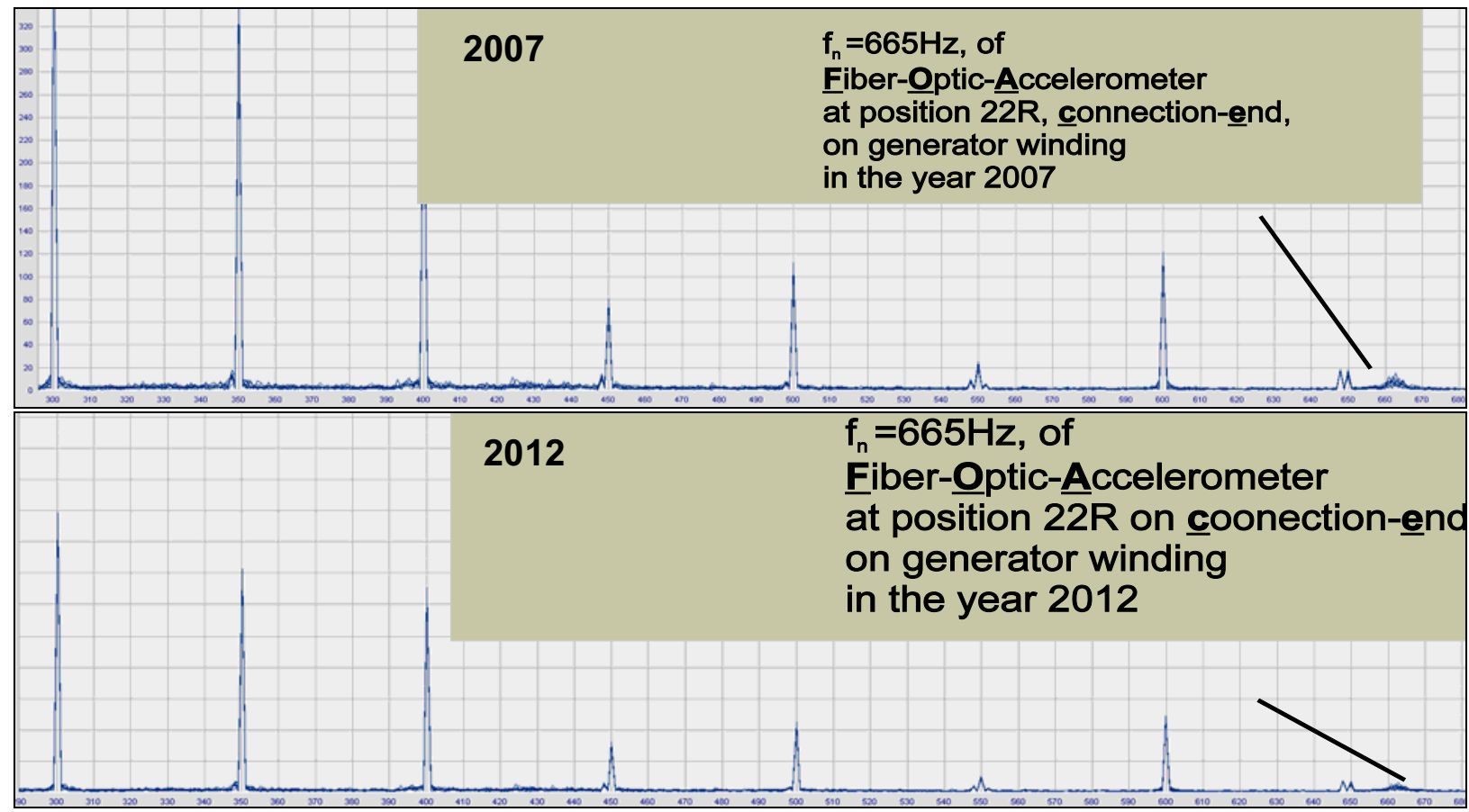

Fig. 6: Sensitivity check of FOA sensor after 5 years of permanent on-side operation Characteristic frequency $f_{n}=665 \mathrm{~Hz}$ of the individual sensor remain unchanged

In Figure 6 a comparison of frequency spectra taken at same FOA sensors in the year 2007 and in 2012 is given, which is a time period of five years of permanent load operation. The two plots document that the eigenform $\mathrm{f}_{\mathrm{n}}=665 \mathrm{~Hz}$ of the vibration sensor remained unchanged during all kind of operational stress within the last five years.

Any aging process, which could have influenced the sensor elements like fiber flexibility, vibration mass fixing or mirror position, would have changed the characteristic frequency $f_{n}=665 \mathrm{~Hz}$ of the sensor, as it is like a manufacturing finger print of each individual vibration sensor. With the original specification from the manufacturer of the vibration sensor, which should include the eigenfrequency $f_{n}$ of the individual device, the long time stability of a fiber optic vibration sensor could be controlled. It only needs recording the trend data of eigenfrequency $f_{n}$ at comparable operating temperature.

During a maintenance standstill of the generator the functionality and possible sensitivity drift could be checked by exciting the vibration sensor with a nearby impact pulse produced with a bump test hammer. The excitation amplitude of the characteristic frequency $\mathrm{fn}$ of each individual FOA sensor depends on the excitation of the global end winding structure. With an impact excitation, e. g. during a modal analysis procedure of the complete end winding basket, it would be possible to verify the FOA sensor condition. The eigenfrequency $f_{n}$ of the vibration sensor is the most valuable criteria for checking long time stability of the sensor as it can be controlled online or offline.

\subsection{Temperature Sensor}

\subsubsection{Application and Measurement Results}

Fiber optic temperature sensors used in large generators are based on FBG principle with up to 12 sensors in series on one fiber only [2] [3]. At stator windings FBG sensor arrays could be implemented for direct temperature measurement at copper conductor on high voltage. Since 2006 FBG temperature sensors have been installed in generators for permanent operation. The sensor location along the slot and involute part of a stator winding bar is shown in Figure 7. 


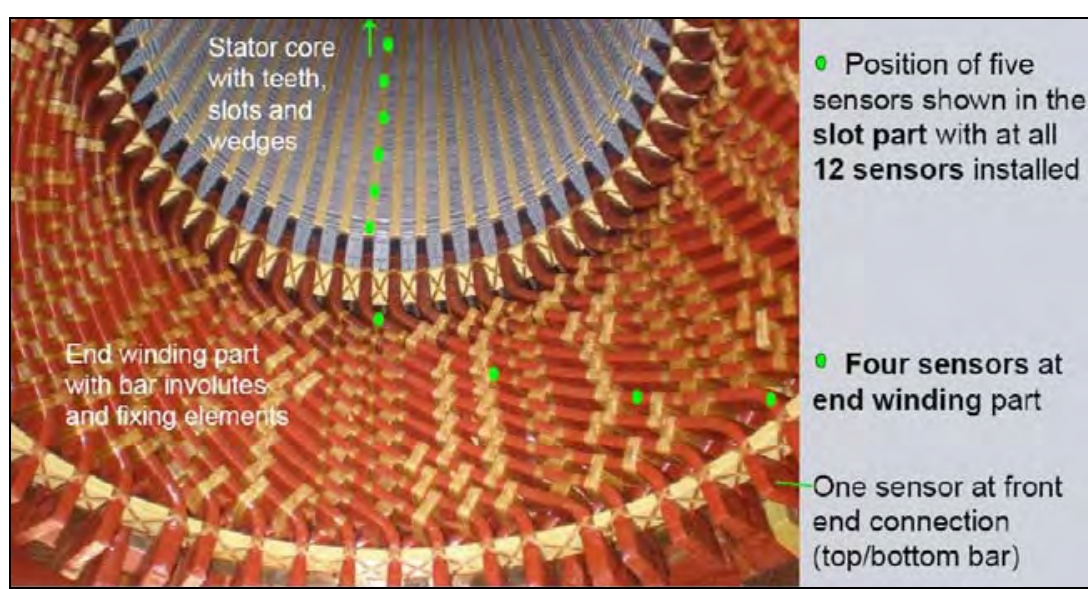

Fig. 7: Bottom half of an indirect cooled generator stator with marked positions of FBG sensors measuring axial distribution of copper conductor temperature

The temperature distribution within the stator winding of the generator during test field run is given in Figure 8. The reliable and sensitive temperature readings at the cooling zones give excellent data for cross-checking of used thermal calculation program [4].

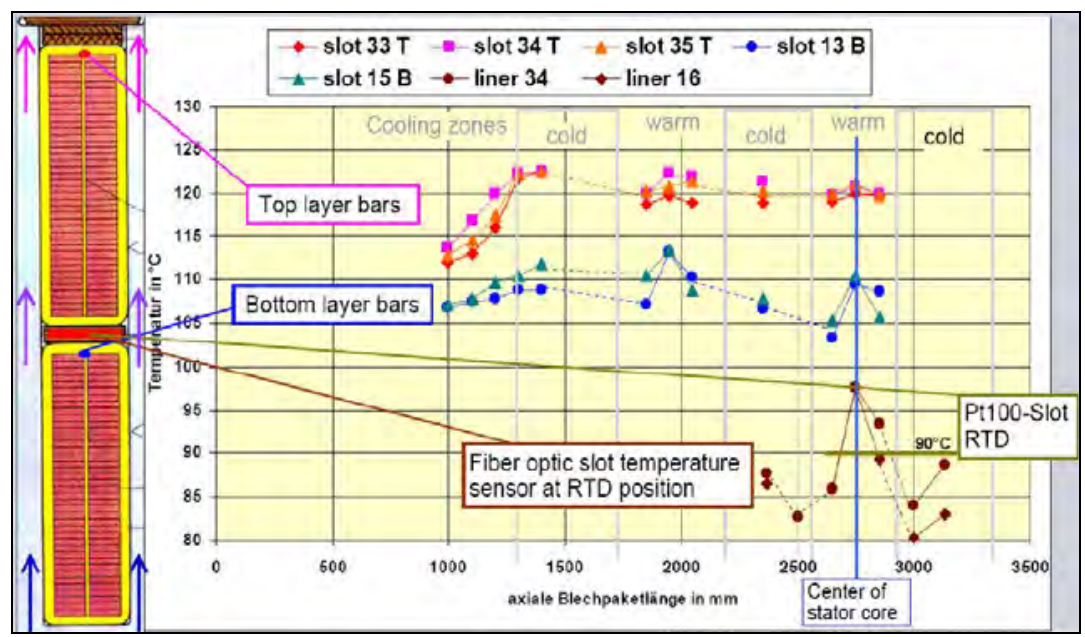

Fig, 8: Axial measured copper conductor temperature distribution at top and bottom layer bars compared with conventional slot RTD reading during test field run

\subsubsection{Long Time Stability of Fiber Optic Temperature Sensors}

As in temperature sensors no moving parts are involved, unlike in accelerometer sensors, they are immune to mechanical vibrations, which are inevitable due to electromagnetic forces in generators. The fiber is made of fused silica and the inscription of the FBG is stable unless a critical temperature is not reached. The maximum operation temperature is however limited by the thermal class of the stator winding insulation system, which is designed for thermal class 155 . It means that temperatures have to be kept below $155^{\circ} \mathrm{C}$ under all circumstances. This temperature limit is well below the limit of $200^{\circ} \mathrm{C}$ of the FBG sensors installed.

Over the many years of in field operation at different type of electric power apparatus there was no sensor related temperature drift observed at all the installed FBG sensors, as far as we can compare measurement data. Usually the generators run near completely throughout the year and given the location of installation comparing there temperature value with a reference is impossible. However for maintenance work, a generator is shut down. After a considerable time for cooling down, the temperature reading from the FBG sensor can be compared with the slot RTD and the cooling air thermometer readings. Both values do agree within $1^{\circ} \mathrm{C}$ usually, which is accurate enough for monitoring purposes. 


\subsection{Strain Sensor}

The use of fiber optic accelerometers is well accepted meanwhile to monitor the condition of the winding overhangs. However it remains an indirect measurement as acceleration sensor are used to measure the amplitude of local winding bar movement. A possible mechanical overstressing or a local pre-damaging of stator bar insulation system, that could occur at some parts of the end winding basket, is mainly caused by high dynamic-mechanical transients or thermo-mechanical stresses due to overload conditions leading to fatigue. Therefore the strain should be measured complementary to the vibration behaviour of the overhang. Small FBG strain sensors were developed, which had the advantage of easy installation on the uneven surface of taped winding bar insulation.

As demonstrated in Figure 9 permanent installation of strain sensors had been performed in 2007 at two top layer stator winding bars of different electrical phase at slot exit region with four FBG strain sensors applied at each bar at different axial locations $(\rightarrow)$ to measure the static and dynamic mechanical tension of the insulation in this highly stressed part of the overhang.

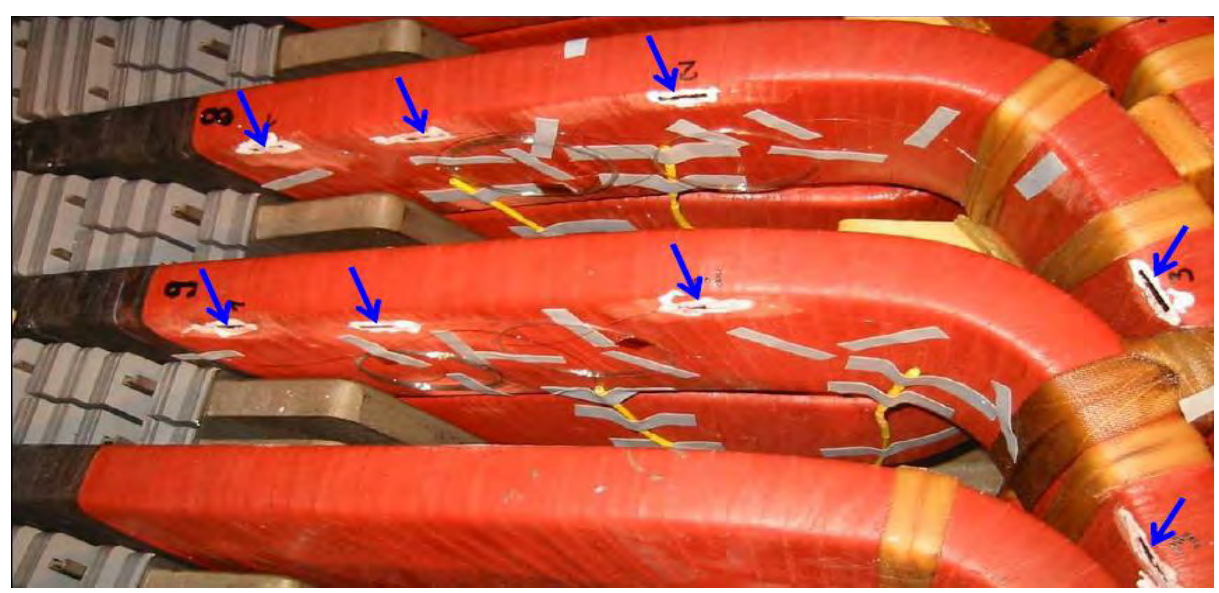

Fig.9: $\quad$ Tiny FBG strain sensors (small black strips marked with blue arrows) fixed with white glue on the surface of stator winding insulation - two top bars at phase separation

The boundary conditions for strain sensors are similar to those for accelerometers. The strain sensor is stretched due to electromagnetic forces acting on the stator bar at 100 cycles per second, or 1 million cycles in about $3 \mathrm{~h}$. After months and moreover years enormous numbers of cycles have been generated. Any fault in the fabrication of the sensors or their installation would have been brought up during operation and ended in fatigue of the sensor.

After 6 years of operation the strain sensors still work showing no drift nor creepage of the fixation. As a measure that the sensor condition has not changed, the FBG spectrum can taken. Figure 10 shows a spectrum of the same chain of two strain sensors in series taken in 2007 after installation and of 2013.
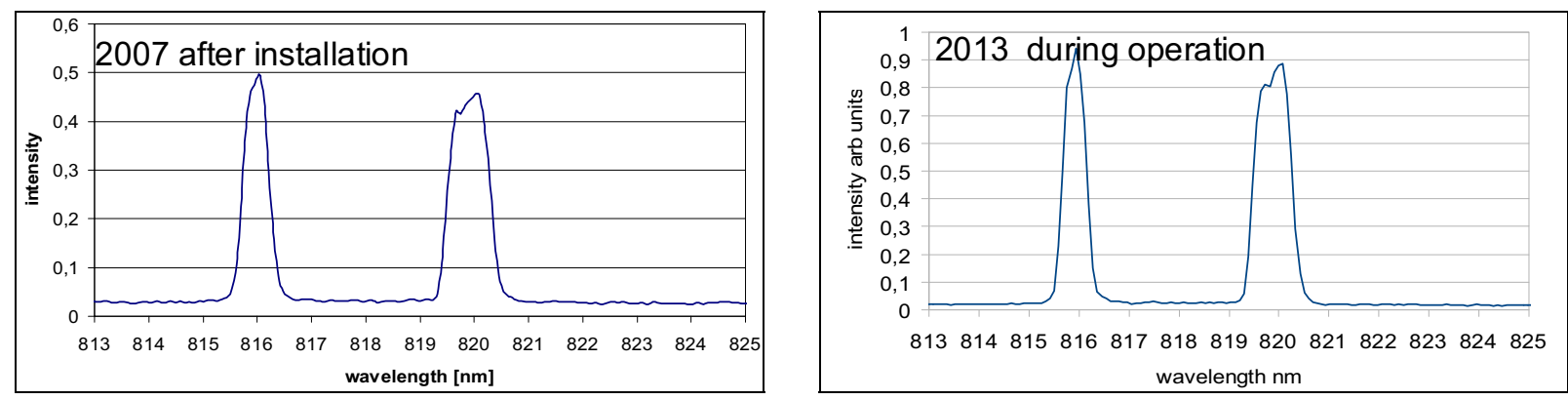

Fig.10: Characteristic wave length spectrum of same chain of two strain sensors in series taken in 2007 after installation and 2013 at generator operation

The sensor at a wavelength of $820 \mathrm{~nm}$ exhibits some broadening due to birefringence induced during installation. After 6 years of permanent operation no significant change can be detected, even the birefringence appear the same. A slight shift in wavelength comes from the fact that the first 
spectrum was taken during installation, when the generator was cold. The second spectrum was taken during full load operation when the generator coil had a surface temperature of about $80{ }^{\circ} \mathrm{C}$.

To summarize, one can say that it is possible to install FBG strain and temperature sensors in electrical generators for permanent and reliable monitoring. These FGB sensors could withstand all operational stresses that are applied to the stator end windings during full load operation and during all kind of thermal, mechanical and electrical transients.

\section{Fiber Optic sensors for generator diagnostics}

The extremely stressed high voltage stator winding and overhangs of a turbine generator need to be carefully controlled to ensure the design life time of about 30 years. Moreover the influence of frequent start-stop-operation on thermal movement and vibration of the end windings has to be surveyed to avoid accelerated aging of the insulation structure due to mechanical fatigue.

Consequently the stator winding basket had to be equipped with fiber optic vibration, temperature [5] and strain sensors to monitor the influence of peak load operation on local and global vibration modes as well as transient mechanical and thermal load stress in the end winding structure [6]. The correlation of this information with the actual load data and operating parameter of the machine offers an improvement in reliability and endurance strength evaluation. Fiber optic sensors are a key technology, because these tiny sensors can be easy implemented during manufacturing process of turbo generators or later on retrofitted during a major maintenance standstill.

So far the following type of fiber optical sensors are installed on large turbine generators for permanent online monitoring of high voltage stator windings and diagnostics:

(1) FOA sensors for measurement of load dependent endwinding vibration behaviour,

(2) FBG temperature sensors for permanent control of winding bar temperature distribution [7],

(3) FBG strain sensors for direct registration of dynamic stator bar deformation at highly stressed endwinding parts during transient load conditions.

In Figure 11 an example of monitoring the dynamic stator bar deformation at highly stressed bending parts of the end windings is given. The surface strain of bar insulation is measured at the narrow and broad side near front end and slot exit. The correlation to generator load represented by stator current, which affects mechanical end winding stress by dynamic electromagnetic forces, is shown for the last five years without any significant increase (Figure 13). The trending of strain data over the years of operation makes confident that the mechanical stator bar structure of copper conductor and high voltage main insulation has not changed and is still in good condition.

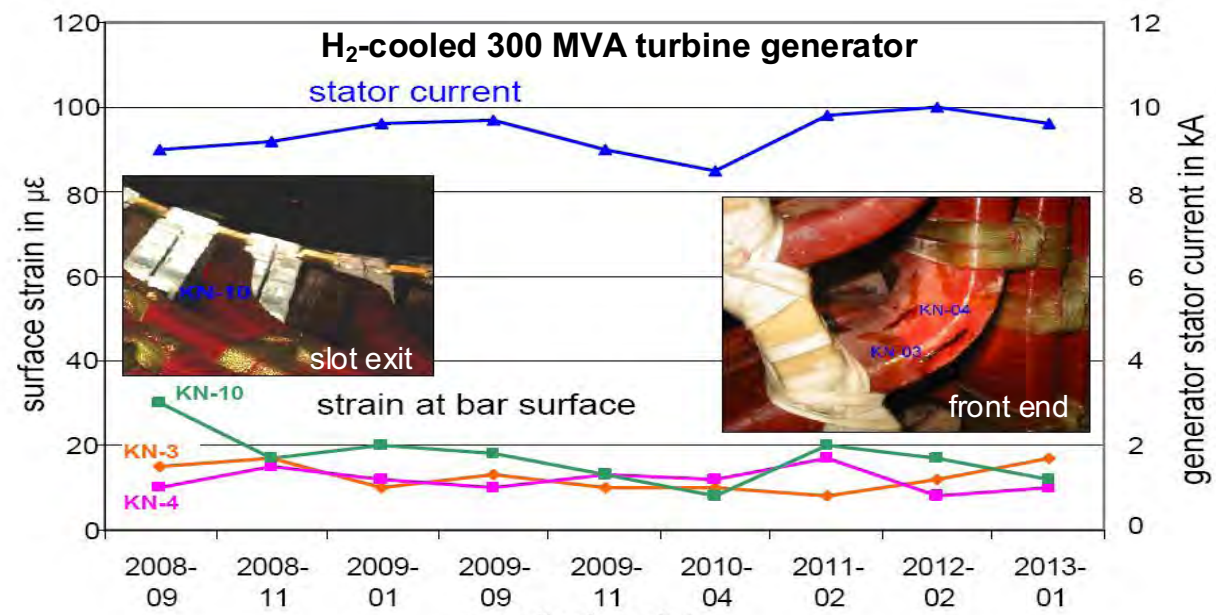

Fig. 11: Monitoring of stator winding strain during last five years in correlation to generator current

\section{Conclusions}

The frequent start-stop-operation together with steep load ramps generate thermal movement, transient forces and vibration to generator stator end winding structure. To control these load stresses large indirect cooled generators have been equipped with fiber optic accelerometer and 
newly designed FBG strain and temperature sensors. To get reliable results for normal aging process and increased wear effects of the monitored object it is necessary to distinguish between the behaviour of the end winding structure and a possible drift of the sensor output signal itself. The long term reliability of fiber optic vibration, temperature and strain sensors had been successfully proved during several years of operation. The following conclusions can be drawn:

1. FOA sensors at well defined locations at end windings gives exact data of load and temperature dependent local and global vibration modes. Possible changes in the behaviour of the endwinding structure would be identified in an early stage and could be supervised by trending.

2. Direct temperature measurement at copper conductor on high potential could control insulation system hot spots and therefore optimize thermal utilization of indirect cooled generators.

3. Copper temperature measurement with FBG sensor arrays avoids thermal overstressing of high voltage insulation system at copper to insulation interface (local hot spot area).

4. Temperature gradient and maximum temperature of the aged insulation system due to reduced thermal conductivity could be monitored during fast load cycles dictated by the grid demands.

5. FBG strain sensors were proved at a hydrogen cooled turbine generator in field application to control the dynamic stator bar deformation at highly stressed bending parts of the end winding.

6. Different kind of fiber optic sensors could be applied for online condition monitoring of the generator when running in peak load operation with high stress categories.

7. Fiber optic sensor technology opens new measurement options with important key information for life time assessment and extension of generator stator windings.

The fiber optic sensor technologies offer new and reliable monitoring and diagnostic tools to control the higher stressed generator parts like stator end windings without increasing the risk of adding instrumentation within generators on high voltage potential. Moreover the analysis of all these data in correlation to characteristic operation parameter lead to important diagnostic information of end winding behaviour within the years. Wear and upcoming weak points could be identified in an early stage and corrective actions could be planned in advance of a major standstill.

\section{References}

[1] ENTSO-E Network Code for Requirements for Grid Connection Applicable to all Generators (entso-e RfG), 26 June 2012, ENTSO-E AISBL, Brussels, Belgium 2012

[2] N. M. Theune, T. Bosselmann, "Multiplexed temperature measurement for power generators", EOS/SPIE Symposium on Applied Photonics, Appl. o. Optical-fiber Sensors, Glasgow, 21.5.-26.5.2000

[3] N. M. Theune, M. Kaufmann, J. Kaiser, M. Willsch, T. Bosselmann, P. Krämmer, „Fiber Bragg Gratings for the Measurement of Direct Copper Temperature of Stator Coil and Bushing Inside Large Electrical Generators“, Proc. OFS 14, Venice, 11.-13.10.2000

[4] J. R. Weidner, "Direct Measurement of Copper Conductor Temperature at Generator Windings with Fibre Bragg Grating (FBG) Sensors", SC A1 Rotating Machines, Contribution PS1/Q1.6, Cigre 2012, Paris, France

[5] T. Tanaka, H. Murayama, K. Hattori, K. Takahashi, "Direct measurement of strand temperature of turbo-generator with FBG sensors" Paper A1-109, Cigre 2012, Paris, France

[6] T. Bosselmann, E. Abromitis, V. Chernogorski, S. Lindholm, R. Roeding, U. Schwanengel, S. Strack, M. Villnow, J. R. Weidner, M. Willsch," Design validation of an air cooled turbo generator by using fiber optic sensors in a shop test", SPIE Defense, Security, and Sensing, Fiber Optic Sensors and Applications IX, Baltimore, 26.4.2012

[7] Wang, Peng; Liu, Jie; Song, Fangchao; Zhao, Hong: Quasi-distributed Temperature Measurement for Stator Bars in Large Generator via Use of Fiber Bragg Gratings, 6th International Forum on Strategic Technology, August 23rd 24th 2011 , pp. $810-813$

\section{Authors}

Dipl.-Ing. Sebastian Strack, Siemens AG, Energy Sector, Fossil Power Generation, Generator Engineering,

Abt. E F PR GN EN SE 22, D-45478 Mülheim a. d. Ruhr, Rheinstrasse. 100

Tel.: 0049-208-456-5171, Fax: 0049-208-456-1847, e-mail: strack.sebastian@siemens.com

Dipl.-Ing. Jürgen Weidner, Siemens AG, Energy Sector, Fossil Power Generation, Generator Engineering,

Abt. E F PR GN QM AE, D-45478 Mülheim a. d. Ruhr, Rheinstrasse. 100

Tel.: 0049-208-456-4542, e-mail: juergen.r.weidner@siemens.com

Dr.-Ing. Thomas Bosselmann, Dipl.-Ing. Michael Villnow, Dr.-Ing. Michael Willsch, Siemens AG, Corporate Technology, Corporate Research and Technologies, Abt. CT T DE HW 3,

D-91058 Erlangen, Günther-Scharowsky-Str. 1, e-mail: michael.willsch@siemens.com 